\title{
Research on Regional Entrepreneurial Ecosystem and Its Operating Mechanism Xingqi $\mathrm{Lu}^{* 1}$
}

\author{
${ }^{1}$ School of Logistics and E-commerce, \\ Zhejian Wanli University \\ Ningbo 315100, China. \\ *Corresponding author Email: 519493987@qq.com
}

\begin{abstract}
The development of entrepreneurial activities is similar to the development of natural organisms. It is a meaningful exploration to study regional entrepreneurial activities by using the theory of ecology. This paper analyzes the development and connotation of the regional entrepreneurship ecosystem, discusses the constituent elements of the regional entrepreneurship ecosystem, and based on the analysis of the interaction between the constituent elements of the regional entrepreneurship ecosystem, puts forward the main operation mechanism of the regional entrepreneurship ecosystem, which generally includes the dynamic mechanism, regulation mechanism, competition mechanism, symbiosis mechanism and integration mechanism, These mechanisms interact and restrict each other, and jointly promote the development of regional entrepreneurship ecosystem towards the established direction.
\end{abstract}

Keywords: Region, Entrepreneurship, Ecosystem, Operation mechanism

\section{INTRODUCTION}

At present, the upsurge of entrepreneurship is booming, but the development of entrepreneurial economy shows that the entrepreneurial failure rate is still high, and entrepreneurial failure has become the norm. Many researchers have studied it from different perspectives. How to create a good regional entrepreneurial environment? How to develop entrepreneurial economy? How to reduce the failure rate of entrepreneurship? Entrepreneurship research has always been the focus of attention. This paper holds that the development of entrepreneurial activities is similar to the development of natural organisms. It is very necessary to introduce the ecosystem theory into the research of entrepreneurship, analyze the entrepreneurial system and entrepreneurial activities with the theory of ecology, and then carry out special research on the entrepreneurial ecosystem and its operation mechanism. This paper analyzes the development and connotation of regional entrepreneurship ecosystem, discusses the elements of regional entrepreneurship ecosystem, and puts forward the main operation mechanism of regional entrepreneurship ecosystem.

\section{THE DEVELOPMENT AND CONNOTATION OF THE CONCEPT OF REGIONAL ENTREPRENEURSHIP ECOSYSTEM}

\subsection{The development of the concept of entrepreneurial ecosystem}

The term "ecosystem" was first put forward by Tansley, a plant ecologist. Tansley (1935) believed that the ecosystem is a unified whole composed of organisms and their living environment. Within a certain time and space, there are interactions between organisms and the physical environment, through material circulation, energy flow and information transmission, The formation of a specific nutritional structure and biodiversity, such a functional unit is the ecosystem[ 1] .Hannan and Freeman (1977) put forward the concept of organizational ecology, which explains the close relationship between enterprise groups and their living environment from the perspective of ecology[2].Since then, scholars have introduced ecosystem into the field of economics and management. Moore (1993) proposed the concept of business ecosystem on the basis of organizational ecology. The relationship between an enterprise and its business 
system is just like the relationship between biology and environment. The development of an enterprise is inseparable from the cooperation of other elements in the business ecosystem[3] .Dunn (2005) first proposed the concept of "entrepreneurial ecosystem" in his article the entrepreneurship ecosystem. This paper studies the entrepreneurial activities and entrepreneurial environment of MIT, and points out that the University and its various entrepreneurial service support institutions provide rich entrepreneurial resources and support for entrepreneurial enterprises. The cooperation between organizations greatly promotes the emergence of all kinds of innovative entrepreneurial activities in Colleges and universities, and helps teachers and students to better implement entrepreneurial behavior, Entrepreneurial enterprises and these organizations together constitute the "entrepreneurial ecosystem" of MIT. Dunn did not clearly define the "entrepreneurial ecosystem", but put forward the rudiment of entrepreneurial ecosystem[4]. In 2006, Cohen put forward the concept of entrepreneurial ecosystem for the first time; The community formed by the interaction subjects in a specific region can achieve sustainable development by supporting and promoting the creation and growth of new enterprises[5].

\subsection{The connotation of regional entrepreneurship ecosystem}

At present, researches have divided the concept of entrepreneurial ecosystem into two categories. One is to regard entrepreneurial ecosystem as the external environment of entrepreneurial enterprises. For example,Isenherg (2010) advocates to improve the entrepreneurial environment by forming an entrepreneurial ecosystem with regional characteristics[6]. $\operatorname{Lin}(2011)$ believes that the entrepreneurial ecosystem is a dynamic balance system composed of new ventures and the entrepreneurial ecological environment on which they depend for their existence and development, which depends on each other, influences each other and develops together[7]. The other group thinks that the entrepreneurial ecosystem is a unified whole composed of the entrepreneurial subject and the external environment. For example, Cai et al. (2016) thinks that the entrepreneurial ecosystem is an organic whole composed of a variety of entrepreneurial participants (including entrepreneurial enterprises and related enterprises and institutions) and their entrepreneurial environment, and they interact with each other, We are committed to improving the overall level of entrepreneurial activities[8]. These studies have gradually clearly defined the connotation of entrepreneurial ecosystem, that is, the whole of entrepreneurial subject and its environment.

\section{THE CONSTITUENT ELEMENTS OF REGIONAL ENTREPRENEURIAL ECOSYSTEM}

\subsection{Basic analysis of the constituent elements}

The regional entrepreneurial ecosystem is a whole composed of the main body of regional entrepreneurial activities and its environment. The main body of regional entrepreneurial activities includes direct participants and indirect participants. The direct participants are start-up enterprises, including new ventures or mature enterprises that carry out internal entrepreneurship. Some of them also include individuals, customers, suppliers and other related enterprises of start-up enterprises that have a direct impact on regional entrepreneurial activities. The indirect participants are organizations and institutions that provide various kinds of support and services for start-up enterprises, including the government, technology transfer enterprises, incubators, incubators, etc Universities and scientific research institutions, intermediary institutions, venture capital and financing institutions, financial institutions and so on, these subjects together constitute a regional entrepreneurial community. Entrepreneurial environment is a collection of external factors in the process of entrepreneurial activities, including various environmental factors that provide basic conditions for the development of regional entrepreneurial activities, such as the political, economic, legal, cultural environment of entrepreneurial activities, which constitute the entrepreneurial environment.

\subsection{Regional entrepreneurship ecosystem model}

In the organic whole of regional entrepreneurship ecosystem, the interaction between participants and participants and environment will affect the level of regional innovation and entrepreneurship activities. In this system, enterprises are the direct participants in innovation and entrepreneurship. Colleges and universities and entrepreneurial talents are the main communicators and practitioners of entrepreneurship. Venture capital is an important support for the entrepreneurial ecosystem, the service institutions are the bridge for entrepreneurship, and the government is an important promoter of the development of the entrepreneurial ecosystem. The core layer of regional entrepreneurship ecosystem is entrepreneurs. Entrepreneurship services are closely related to entrepreneurs, providing them with the funds, government, technology, market and social network required by the entrepreneur group. The peripheral level of regional entrepreneurship ecosystem is an essential factor of entrepreneurial environment, such as political 
environment, economic environment, legal environment and cultural environment. These elements supporting entrepreneurship are interrelated and interdependent with the entrepreneurial population, which constitute the regional entrepreneurship ecosystem, as shown in Figure 1.

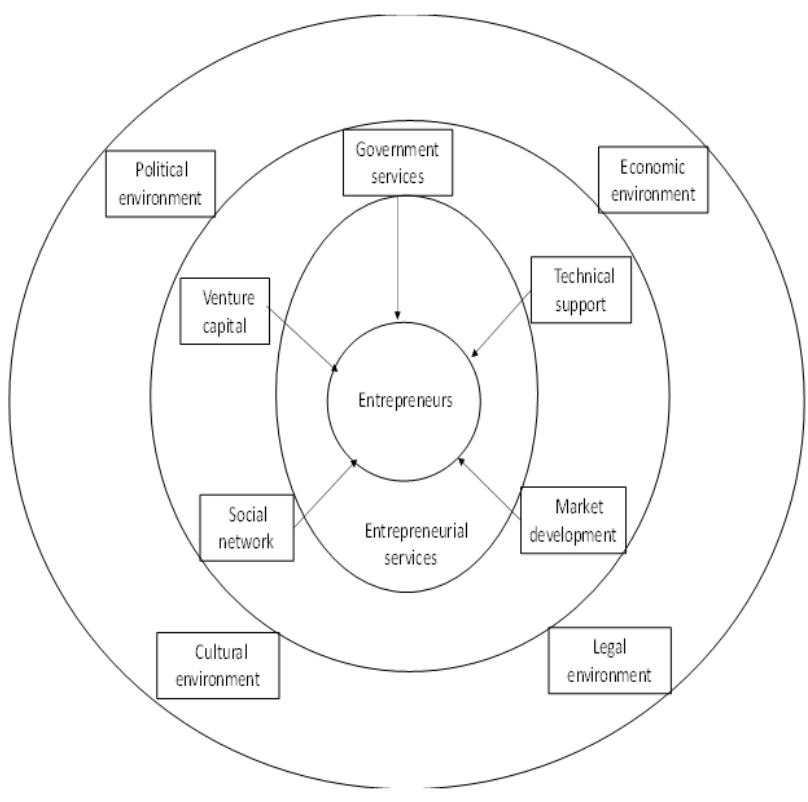

Figure 1 Regional entrepreneurship ecosystem

\section{OPERATION MECHANISM OF REGIONAL ENTREPRENEURSHIP ECOSYSTEM}

The operation mechanism of regional entrepreneurship ecosystem refers to the structure, function and mutual relationship of the constituent elements that affect the operation of regional entrepreneurship ecosystem in the regular operation of regional entrepreneurship ecosystem, as well as the mechanism and operation mode of these factors. Based on the analysis of regional entrepreneurship ecosystem, its operation mechanism generally includes dynamic mechanism, Regulation mechanism, competition mechanism, symbiosis mechanism and integration mechanism, these mechanisms interact and restrict each other, and jointly promote the development of regional entrepreneurship ecosystem towards the established direction.

\subsection{Dynamic mechanism}

Based on the common value goal of the entrepreneurial ecosystem, the dynamic mechanism fully mobilizes the enthusiasm, initiative and creativity of each entrepreneurial subject to participate in entrepreneurial activities, gives full play to the functions of each subject, and continuously increases the social value of the whole system, including promoting the internal driving force of regional core competitiveness and economic development through interest driving, Based on the external inducement of institutional construction and fiscal and tax policies to create a good entrepreneurial environment, based on the key supporting force provided by financing channels and social networks, based on the collaborative driving force of entrepreneurship and entrepreneurial team formation, and based on the advantages of colleges and universities, scientific research institutes and various intermediary service institutions and media institutions to create a favorable social and cultural atmosphere, To provide auxiliary catalytic force for entrepreneurial activities, in order to achieve specific regional entrepreneurial economic development goals.

\subsection{Regulation mechanism}

The regional entrepreneurial ecosystem is in dynamic development, and the entrepreneurial participants will continue to enter or exit. With the change of the number or position of different entrepreneurial participants, the evolution process of the system often goes through the process from balance to imbalance, and then from imbalance to new balance. Any entrepreneurial ecosystem will strive to achieve its long-term stable development, It needs the selfregulation of the participants. Through the interaction, the quality of the system elements can be improved. When the constituent elements are complementary in the change, the regulation mechanism can play its due role to promote the development of regional entrepreneurial activities, so as to enhance the overall adaptability and core competitiveness of the Regional Entrepreneurial ecosystem.

\subsection{Competition mechanism}

Within the regional entrepreneurship ecosystem, there is a relationship of cooperation and competition between the constituent elements. The healthy development and healthy operation of the regional entrepreneurship ecosystem is inseparable from the reasonable competition of the participants. This is because in the regional entrepreneurship ecosystem, the entrepreneurial participants are in the same regional entrepreneurship ecosystem. Each population in the regional entrepreneurship ecosystem has its own niche and function, and each population has its own advantages and characteristics, with different niche. The two populations in the system can not occupy the same niche at the same time, so we must change the way of resource utilization or action mode, so as to produce their own comparative advantage. Reasonable competition among various groups in the system can achieve complementary advantages, so as to make rational use of resources. 


\section{4. symbiosis mechanism}

In the development and operation of regional entrepreneurship ecosystem, various groups reduce costs and risks through cooperation, and improve the success rate and return rate of entrepreneurship. Based on the extensive cooperation and resource sharing of various entrepreneurial participants, the Regional Entrepreneurial ecosystem has formed a symbiotic relationship of complementary advantages and mutual benefit. Among them, the government, enterprises, various incubators, colleges and universities, scientific research institutes, investment institutions, financial institutions, intermediary service institutions and other main bodies constitute a symbiotic unit, including policies, systems, management experience, funds, management experience Technology and other resources constitute the symbiotic matrix, energy, material, information transmission and talent flow path and carrier constitute the symbiotic interface, and all factors outside the symbiotic unit constitute the symbiotic environment. Within the Regional Entrepreneurial ecosystem, the populations are mutually beneficial and symbiotic, showing better competitiveness and adaptability, and achieving a winwin situation for two species or multiple species through resource integration and complementary advantages.

\subsection{Integration mechanism}

Integration mechanism means that with the development of regional entrepreneurship, regional entrepreneurship ecosystem can effectively gather and allocate resources, and the role of resource integrator is increasingly obvious. The healthy operation and healthy development of regional entrepreneurship ecosystem must make the system have the function of effectively gathering and allocating entrepreneurial resources. The characteristic regional entrepreneurship ecosystem has the corresponding mechanism and operation mode. In the regional entrepreneurship ecosystem, each entrepreneurial participant integrates and shares resources according to their own status around specific goals and visions. Entrepreneurial resources are the basis of regional entrepreneurial activities, including policy, talent, capital, infrastructure, technology, information, organization, social network and so on. The development of regional entrepreneurial activities is inseparable from all kinds of entrepreneurial resources provided by external support elements. The unique resource allocation mechanism of Regional Entrepreneurial ecosystem enables the resources provided by different external organizations to appear as a systematic whole and fully serve regional entrepreneurial activities.

\section{CONCLUSION}

(1) Regional entrepreneurship ecosystem refers to the unity of mutual influence and common development formed by the continuous process of material circulation, energy exchange, information diffusion and talent flow between the entrepreneurship related subjects and the external environment in a certain space.

(2) In the regional entrepreneurship ecosystem, the core layer is the entrepreneur, and the entrepreneurship service is closely related to the entrepreneur to provide the capital, government, technology, market and social network needed by the entrepreneur group. The peripheral layer of the regional entrepreneurship ecosystem is the essential entrepreneurial environment element for the entrepreneur.

(3) The elements of regional entrepreneurship ecosystem are interrelated, influenced and interacted with each other. Its operation mechanism generally includes dynamic mechanism, regulation mechanism, competition mechanism, symbiosis mechanism and integration mechanism. These mechanisms interact and restrict each other, and jointly promote the development of regional entrepreneurship ecosystem towards the established direction.

\section{REFERENCES}

[1] A G Tansley. The use and abuse of vegetational concepts and terms, Ecology 16(3) (1935) 284307. DOI: https://doi.org/10.2307/1930070 .

[2] M T Haiman, J H Freeman. The population ecology of organizations, American Journal of Sociology 82(5) ( 1977 ) 929-964.DOI : $10.1086 / 226424$

[3] J F Moore. Business ecosystems and the view from the firm, Antitrust Bulletin 51(1) (2006) 3133. DOI: $10.1177 / 0003603 \times 0605100103$

[4] K Dunn.The entrepreneurship ecosystem, MIT Technology Review 1(19)（2005）232-235.

[5] B Cohen. Sustainable valley entrepreneurial ecosystems, Business Strategy and the Environment 15(1)( 2006)1-14.DOI : $10.1002 /$ bse. 428

[6] D J Isenherg. How to start an entrepreneurial revolution,Harvard Business Review 88 (6) (2010)40-50.

[7] S Lin.The Concept Development and Operation Mechanism of Entrepreneurial Ecosystan,Journal of Central University of Finance \& Economics (4)(2011)58-62. DOI: CNKI:SUN:ZYCY.0.201104-011

[8] L Cai , X Q Peng and S Nambisan et al.Entrepreneurial Ecosystem: Review and Prospects,Jilin University Journal Social Sciences Edition (1)( 2016)5-16. DOI : 10 . $15939 / \mathrm{j}$. jujsse. 2016. 01. 001 